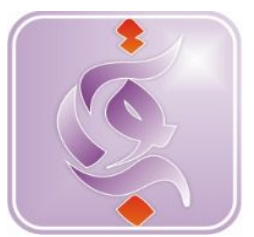

\title{
HUBUNGAN ANTARA DUKUNGAN SOSIAL DENGAN SELF REGULATED LEARNING SISWA SMK
}

Received: 08 ${ }^{\text {th }}$ September 2019; Revised: $06^{\text {th }}$ October 2019; Accepted: $22^{\text {th }}$ October 2019

\begin{abstract}
Ayu Merisa
Fakultas Psikologi, Universitas Putra Indonesia "YPTK" Padang

Email: aiyu.merissa@gmail.com

Purwanti Endah Rahayu

Fakultas Psikologi, Universitas Putra Indonesia "YPTK" Padang

Email: yukepsikolog@yahoo.com

Krisnova Nastasia

Fakultas Psikologi, Universitas Putra

Indonesia "YPTK" Padanga

Email: krisnova88@gmail.com
\end{abstract}

\begin{abstract}
Abstrack. Penelitian ini bertujuan untuk mengetahui hubungan antara dukungan sosial dengan self regulated learning pada siswa SMK Negri 4 Padang.Variabel bebas dalam penelitian ini adalah dukungan sosial dan variabel terikat adalah self regulated learning. Alat ukur yang digunakan dalam penelitian ini adalah skala dukungan sosial dan skala self regulated learning.Teknik pengambilan sampel dalam penelitian ini menggunakan teknik Proportionate Stratified Random Sampling. Sampel dalam penelitian ini adalah 290 orang siswa SMK Negri 4 Padang. Uji validitas dan reliabilitas pada penelitian ini menggunakan teknik Alpha Cronbach. Hasil koefisien validitas pada skala dukungan sosial bergerak dari $\mathrm{r}_{\mathrm{ix}}=0,301$ sampai dengan $\mathrm{r}_{\mathrm{ix}}=0,762$ dengan koefisien reliabilitas sebesar $\alpha=0,925$ sedangkan pada skala self regulated learning bergerak dari $\mathrm{r}_{\mathrm{ix}}=0,303$ sampai dengan $\mathrm{r}_{\mathrm{ix}}=0,843$ dengan koefisien reliabilitas sebesar $\alpha=0,927$. Berdasarkan analisis data, diperoleh nilai koefisien korelasi sebesar 0,542 dengan taraf signifikansi 0,000 yang berarti hipotesis diterima. Hal ini menunjukkan bahwa ada hubungan yang signifikan antara dukungan sosial dengan self regulated learning pada siswa SMK Negri 4 Padang.
\end{abstract}

Kata Kunci: Dukungan Sosial, Self Regulated Learning, Siswa

\section{PENDAHULUAN}

Perkembangan suatu negara dilihat dari kualitas sumber daya manusia yang dimiliki. Kualitas sumber daya manusia mencerminkan wawasan, pengetahuan, pemikiran kritis, dan tanggung jawab sosial., salah satu yang harus ditempuh adalah menciptakan sumber daya manusia yang baik dan berkualitas melalui pendidikan. Pendidikan merupakan suatu kegiatan yang secara sadar dan disengaja, serta penuh tanggung jawab yang dilakukan oleh orang dewasa kepada anak sehingga timbul interaksi dari keduanya agar anak tersebut mencapai kedewasaan yang dicita-citakan dan berlangsung secara terus menerus (Ahmadi \& Uhbiyati dalam Afriansyah, 2014).

Untuk melihati perkembangan peserta didik dalam mencapai tujuanya, khususnya para remaja, adalah dengan memahami tugas perkembangan masa remaja. Tugas perkembangan masa remaja difokuskan pada upaya meningkatkan sikap dan perilaku kekanak-kanakan serta berusaha untuk mencapai kemampuan bersikap dan berperilaku secara dewasa.(dalam Ali \& Asrori, 2012 ).

Peneliti tertarik untuk melakukan penelitian di SMK, berdasarkan penelitian yang pernah di lakukan Hediati, bahwa Siswa yang mempunyai minat dan prestasi rendah akan merasa tidak mampu jika melanjutkan ke SMA atau jenjang yang lebih tinggi, sehingga akan lebih memilih SMK, dengan alasan pelajaran lebih khusus dan mudah serta siap bekerja nantinya. lingkungan masyarakat yang lebih memandang SMK akan lebih mengutamakan keterampilan dan kesiapan kerja bukan pada prestasi akademik seperti di SMA. Hal ini menimbulkan permasalahan rendahnya minat siswa dalam pembelajaran akademik lebih banyak di temukan di SMK dibandingkan dengan SMA. (dalam Hadiati, 2013) 
Berdasarkan wawancara awal pada tanggal 24 september 2017 kepada wakil kurikulum (WKK) di SMK Negeri 4 Padang bahwa siswa hanya menerima pelajaran yang diberikan guru, beberapa siswa yang mendapat nilai rendah, juga ada yang tidak membuat tugas dengan alasan tidak memahami pelajaran yang diberikan guru dan adanya budaya mengobrol di kelas. Orangtua siswa dan masyarakat yang memiliki rutinitas tinggi sehingga tidak memiliki waktu untuk mengontrol, mengawasi dan mendidik putra-putrinya dan cenderung menyerahkan seluruh tanggung jawab pendidikan kepada guru.

Hal ini juga didukung dengan wawancara kepada sepuluh orang siswa SMK Negeri 4 Padang, Siswa memberikan alasan mengaku tidak bisa mengatur waktu untuk belajar dan membuat tugas sekolah karna lebih banyak menghabiskan waktu untuk bermain dengan teman. Berdasarkan informasi siswa juga tidak memanfaatkan fasilitas lingkungan sekolah malas dalam mencari referensi bacaan di perpustakaan. Saat pembelajaran dikelas siswa sulit untuk mengatur dirinya ketika tidak paham dengan materi yang diajarkan beberapa siswa memilih untuk mengobrol dengan teman. siswa juga mengaku tidak memiliki terget pencapaian nilai yang tinggi dalam mempersiapkan ujian kurangnya motivasi siswa dalam belajar.

Fenomena lain yang ditemukan, siswa mengalami kesulitan dalam dalam persahabatan atau belajar akrab dengan teman sebaya. Masalah terbanyak adalah mudah marah dan mudah tersinggung. Informasi dari beberapa siswa ,ada yang memilih berkelahi dengan alasan tersinggung saat ada teman yang mengejek atau mengeluarkan kata - kata yang tidak baik. siswa mengekspresikan emosi marahnya dengan mengumbar secara berlebihan, seperti bersuara keras, membentak, memukul, dan berkelahi dengan teman hal tersebut mencerminkan siswa kurangnya kemampuan siswa dalam mengelola emosi. Penelitian ini sebelumnya sudah pernah dilakukan oleh Fatimah Saguni (2014) yang berjudul "Hubungan Penyesuaian Diri, Dukungan Sosial Teman Sebaya dan Self Regulated Terhadap Motivasi Belajar Siswa Kelas Akselerasi SMP Negril 1 PALU. Perbedaan dengan penelitian sebelumnya dalam hal subjek penelitian, tempat penelitian, dan tahun penelitian.

Berdasarkan uraian dan latar belakang yang telah dikemukakan di atas, maka peneliti tertarik untuk melakukan penelitian dengan judul Hubungan antara Dukungan Sosial dengan Self
Regulated Learning pada Siswa di SMK Negeri 4 Padang.

\section{METODE}

Penelitian kuantitatif adalah studi ilmiah sistematis tentang suku cadang dan fenomena dan hubungan mereka. Tujuan penelitian kuantitatif adalah untuk mengembangkan dan menggunakan model matematika, teori dan / atau hipotesis yang berkaitan dengan fenomena alam. Proses pengukuran merupakan bagian sentral dari penelitian kuantitatif karena memberikan hubungan mendasar antara pengamatan empiris dan ekspresi matematis hubungan kuantitatif.

Penelitian kuantitatif adalah definisi, pengukuran data kuantitatif dan statistik obyektif melalui perhitungan ilmiah yang berasal dari sampel orang atau warga yang diminta untuk menjawab sejumlah pertanyaan tentang survei untuk mengetahui frekuensi dan persentase.

\section{Indentifikasi Variabel Penelitian}

Menurut Sugiyono (2014) variabel penelitian adalah suatu atribut atau sifat atau nilai dari orang, objek atau kegiatan yang mempunyai variasi tertentu yang ditetapkan oleh peneliti untuk dipelajari dan kemudian ditarik kesimpulannya. Adapun variabel yang diukur dalam penelitian ini adalah sebagai berikut:

$$
\begin{aligned}
& \text { variabel dependen } \\
& \text { Learning }(\mathrm{Y}) \\
& \text { variabel independen }
\end{aligned}
$$

1. Populasi

Populasi adalah wilayah generalisasi yang terdiri atas objek atau subjek yang mempunyai kualitas dan karakteristik tertentu yang ditetapkan peneliti untuk dipelajari dan kemudian ditarik kesimpulannya (Sugiyono, 2014) [12]. Populasi dalam penelitian ini adalah siswa SMK Negri 4 Padang yang berjumlah 1187 orang.

2. Sampel

Teknik pengambilan sampel yang digunakan dalam penelitian ini adalah stratified random sampling. Teknik ini digunakan bila populasi mempunyai anggota atau unsur yang tidak homogen dan berstrata secara proporsional (Sugiyono, 2014) ${ }^{[12]}$. Strata yang dimaksudkan dalam penelitian ini yaitu tingkatan kelas X, XI, XII. Penentuan besarnya sampel yang akan diambil dengan menggunakan rumus yang dikemukakan oleh 
Issac dan Michael (dalam Sugiyono, 2014). Dari perhitungan menggunakan rumus tersebut maka sampel dalam penelitian ini adalah sebanyak 290 siswa SMK Negri 4 Padang.

Teknik Pengambilan Data

Alat ukur

Menurut Azwar (2016) skala sebagai alat ukur dalam psikologi memiliki karakteristik khusus yang membedakannya dari berbagai bentuk pengumpulan data yang lain seperti angket (questionnaire), daftar isian, inventori. Bentuk skala yang digunakan untuk mengukur regulasi dirimenggunakan empat alternatif jawaban, yaitu SS (Sangat Setuju), S (Setuju), TS (Tidak Setuju), STS (Sangat Tidak Setuju). Peneliti tidak menggunakan pilihan jawaban tengah "N" (Netral).

\section{Skala Self Regulated Learning}

Skala Self Regulated Learning diukur dengan menggunakan skala Self Regulated Learning menurut zimmerman ( dalam Herdiati , 2014) tentang aspek-aspek yang terdapat dalam self regulated learning diantaranya terdiri dari metakognisi, motivational, bhehavioral atau perilaku.

Skala Dukungan Sosial

Skala dukungan sosial diukur dengan menggunakan skala dukungan sosial berdasarkan teori dari House (dalam Smet, 1994) tentang dimensi dukungan sosial yaitu dukungan emosional, dukungan penghargaan, dukungan instrumental dan dukungan informasi.

\section{Uji Coba Alat Ukur}

Peneliti terlebih dahulu melakukan uji coba atau try out yangbertujuan untuk menyeleksi aitem-aitem mana yang valid dan reliabel agar dapat digunakan dalam penelitian sesungguhnya. Uji coba alat ukur penelitian dilakukan pada tanggal 10 januari 2018 kepada 30 siswa SMK Negeri 4 Padang yang memiliki karakteristik yang sama dengan subjek penelitian.

\section{Uji Validitas dan Reliabilitas}

Validitas berasal dari kata validity yang mempunyai arti sejauh mana ketepatan dan kecermatan suatu alat ukur dalam melakukan fungsi ukurnya (Azwar, 2016). Kriteria pemilihan aitem berdasarkan korelasi aitem total biasanya digunakan batasan rix $\geq 0,30$. Semua aitem yang mencapai koefisien korelasi minimal 0,30 daya pembedanya dianggap memuaskan. Aitem yang memiliki nilai kurang dari 0,30 dapat diinterpretasikan sebagai aitem yang memiliki daya diskriminasi rendah dan batasan ini merupakan suatu konvensi (Azwar, 2016).

Sedangkan Reliabilitas dinyatakan oleh koefisien reliabilitas $\left(\mathrm{r}_{\mathrm{xx}}{ }^{\prime}\right)$ dalam rentang dari 0 sampai dengan 1,00. Semakin tinggi keofisien reliabilitas mendekati angka 1,00 berarti semakin tinggi reliabilitas dan koefisien yang semakin rendah mendekati yang angka 0 berarti semakin rendah reliabilitas (Azwar, 2016) ${ }^{[4]}$. Pada umumnya reliabilitas telah dianggap memuaskan bila koefisiennya mencapai minimal $\mathrm{r}_{\mathrm{xx}}=0,900$ (Azwar, 2014).

Skala Dukungan Sosial validitasnya ditetapkan sebesar 0,25 sehingga diperoleh hasil dari jumlah aitem awal 40 pernyataan, gugur 12 aitem sehingga jumlah aitem yang valid adalah 28 pernyataan, dengan nilai corrected item-total correlation berkisar antara 0,301 sampai dengan 0,762 dengan koefisien reliabilitas $\alpha=0,925$. Skala self regulated learning koefisien validitasnya ditetapkan sebesar 0,30 sehingga diperoleh hasil dari jumlah aitem awal 30 pernyataan, gugur 5 aitem sehingga jumlah aitem yang valid adalah 25 pernyataan, dengan nilai corrected item-total correlation berkisar antara 0,303 sampai dengan 0,843 dengan koefisien reliabilitas $\alpha=0,927$

\section{Hasil dan Pembahasan}

Peneliti terlebih dahulu dengan menyebarkan skala dukungan sosial dan self regulated learning. Pengambilan data dimulai pada hari pada hari selasa tanggal 16 Januari 2018. Skala yang telah diisi oleh siswa SMK Negri 4 Padang langsung dikembalikan kepada peneliti.

\section{Uji Normalitas}

Uji normalitas dalam penelitian ini menggunakan uji Kolmogorov-Smirnov. Priyatno (2008) menyatakan bahwa data yang dinyatakan berdistribusi normal jika signifikansi (p) lebih besar dari 0,05. Berdasarkan hasil pengolahan data dengan 
menggunakan bantuan program komputer, maka diperoleh hasil sebagai berikut:

Tabel 1: Uji Normalitas Sebaran Skala Dukungan Sosial dengan Self Regulated Learning

\begin{tabular}{|c|c|c|c|c|}
\hline Variabel & $\mathbf{N}$ & $\mathbf{K S Z}$ & $\mathbf{P}$ & Sebaran \\
\hline Dukungan & \multirow{2}{*}{248} & 0,819 & 0,5 & \multirow{2}{*}{ Normal } \\
Sosial & & & 13 & \\
\hline Self & & & 0, & \\
Regulated & 248 & 0,74 & 6 & Normal \\
Learning & & 8 & 3 & \\
\hline
\end{tabular}

Berdasarkan tabel 4.5 di atas, maka diperoleh nilai signifikansi pada skala dukungan sosial diperoleh nilai signifikansi sebesar $\mathrm{p}=$ 0,513 dengan $\mathrm{KSZ}=0,819$, hasil tersebut menunjukan bahwa nilai $\mathrm{p}>0,05$, artinya sebaran terdistribusi secara normal, sedangkan untuk skala self regulated learning sebesar $\mathrm{p}=0.631$ dengan $\mathrm{KSZ}=0,748$, hasil tersebut menunjukan bahwa nilai $\mathrm{p}>0,05$, artinya sebaran skala self regulated learning terdistribusi secara normal.

\section{Uji Linieritas}

Uji linieritas dilakukan untuk mengetahui apakah data variabel bebas berkorelasi secara linier dengan variabel terikat. Dikatakan linier apabila nilaip $<0,05$ (Priyatno, 2008) ${ }^{[13]}$. Berdasarkan hasil pengolahan data dengan menggunakan bantuan program komputer, maka diperoleh hasil sebagai berikut:

Tabel 2 : Linieritas Skala Dukungan Sosial dengan Self Regulated Learning

\begin{tabular}{|c|c|c|c|c|}
\hline $\mathbf{N}$ & Df & $\begin{array}{c}\text { Mean } \\
\text { Square }\end{array}$ & F & P \\
\hline 248 & 1 & 5424,194 & 102,466 & 0,000 \\
\hline
\end{tabular}

Berdasarkan tabel 4.6 di atas, diperoleh nilai $F=102,466$ dengan signifikansi sebesar $\mathrm{p}=0,000(\mathrm{p}<0,05)$, artinya varians pada skala dukungan sosial dan self regulated learning tergolong linear.

\section{Uji Hipotesis}

Pengolahan data penelitian tentang hubungan antara Dukungan Sosial dengan Self Regulated Learning kepada 290 siswa SMK Negri 4 Padang menggunakan teknik korelasi product moment dari Pearson dengan menggunakan bantuan program komputer, dapat dilihat pada tabel berikut:

Tabel 3 : Uji Korelasi Antara Skala Dukungan Sosial dengan Self Regulated Learning

\begin{tabular}{|c|c|c|c|c|}
\hline $\begin{array}{c}\text { Nilai } \\
\text { Korela } \\
\text { si (r) }\end{array}$ & $\begin{array}{l}( \\
\alpha \\
)\end{array}$ & $\begin{array}{c}\text { R } \\
\text { Squar } \\
\text { e }\end{array}$ & $\mathbf{p}$ & Kesimpulan \\
\hline 0,542 & $\begin{array}{l}0 \\
1\end{array}$ & 0,398 & $\begin{array}{c}0,0 \\
00\end{array}$ & $\begin{array}{lr}\text { sig } & \text { (2-tailed) } \\
0,000< & <, 01 \\
\text { level } & \text { of } \\
\text { significant }(\alpha), \\
\text { berarti hipotesis } \\
\text { diterima }\end{array}$ \\
\hline
\end{tabular}

Berdasarkan hasil uji korelasi di atas, terlihat korelasi yang signifikan antara dukungan sosial dan self regulated learning siswa SMK Negri 4 Padang, yaitu sebesar $r=0,542$ dengan taraf signifikansi $\mathrm{p}=0,000$. Hal ini menunjukkan adanya korelasi yang berarah positif, yang artinya semakin tinggi dukungan sosial maka semakin tinggi self regulated learning. Begitu juga sebaliknya, semakin rendah dukungan sosial maka semakin rendah self regulated learning. Hal ini diperkuat dengan hasil uji signifikansi dengan bantuan IBM SPSS Statisticversi 20.0, didapatkan $\mathrm{p}=0,000<0,01$ level of significant $(\alpha)$, yang berarti terdapat hubungan yang signifikan antara hubungan antara dukungan sosial dengan self regulated learning.

Berikut tabel deskriptif statisitik dari variabel dukungan sosial dan self Regulated Learning berdasarkan mean empirik sebagai berikut:

\begin{tabular}{|c|c|c|c|c|c|}
\hline \multicolumn{6}{|c|}{$\begin{array}{c}\text { Descriptive Statistic Dukungan Sosial dan Self } \\
\text { Regulated Learning } \\
\text { Descriptive Statistics }\end{array}$} \\
\hline & $\mathrm{N}$ & $\begin{array}{l}\text { Mini } \\
\text { mum }\end{array}$ & $\begin{array}{l}\text { Maxi } \\
\text { mum }\end{array}$ & $\begin{array}{c}\mathrm{Me} \\
\text { an }\end{array}$ & $\begin{array}{l}\text { Std. } \\
\text { Deviatio } \\
\mathrm{n}\end{array}$ \\
\hline $\begin{array}{l}\text { Dukungan } \\
\text { Sosial } \\
\text { Self } \\
\text { Regulated } \\
\text { Learning } \\
\text { Valid N } \\
\text { (listwise) }\end{array}$ & $\begin{array}{r}24 \\
8 \\
24 \\
8 \\
24 \\
8\end{array}$ & 51 & 115 & $\begin{array}{r}85,7 \\
0 \\
73,5 \\
8\end{array}$ & 11,681 \\
\hline
\end{tabular}


Berdasarkan hasil penelitian, maka dapat dilakukan pengelompokan yang mengacu pada kriteria pengkategorisasian dengan tujuan menempatkan individu kedalam kelompok-kelompok yang terpisah secara berjenjang menurut suatu kontinum berdasarkan atribut yang diukur (Azwar, 2014) ${ }^{[4]}$ sebagai berikut:

Tabel 4 : Norma Kategori Variabel

\begin{tabular}{|c|c|}
\hline Norma & Kategorisasi \\
\hline$X<(\mu-1,0 \sigma)$ & Rendah \\
\hline$(\mu-1,0 \sigma) \leq X<(\mu+$ & Sedang \\
$1,0 \sigma)$ & \\
\hline$(\mu+1,0 \sigma) \leq X$ & Tinggi \\
\hline
\end{tabular}

Keterangan :

X : Skor mentah sampel

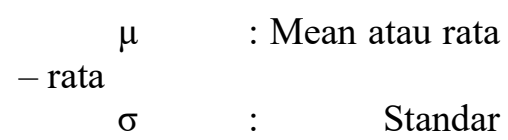

Deviasi

Berdasarkan norma diatas, maka diperoleh kategorisasi subjek penelitian pada variabel dukungan sosial dan self regulated learning sebagai berikut :

Tabel 5 : Kategori Dukungan Sosial dan Self

\begin{tabular}{|c|c|c|c|c|}
\hline \multicolumn{5}{|c|}{ Regulated Learning } \\
\hline Variabel & Skor & Jumlah & $\begin{array}{c}\text { Persentas } \\
\text { e }(\%)\end{array}$ & $\begin{array}{c}\text { Kategor } \\
\text { i }\end{array}$ \\
\hline \multirow{3}{*}{$\begin{array}{c}\text { Dukunga } \\
\text { n Sosial }\end{array}$} & $X<74$ & 45 & $18,14 \%$ & Rendah \\
\hline & $\begin{array}{l}74 \leq X \\
<97\end{array}$ & 154 & $53,28 \%$ & Sedang \\
\hline & $X \geq 97$ & 49 & $19,75 \%$ & Tinggi \\
\hline \multirow{3}{*}{$\begin{array}{c}\text { Self } \\
\text { Regulate } \\
d \\
\text { Learning }\end{array}$} & $X<65$ & 40 & $16,12 \%$ & Rendah \\
\hline & $\begin{array}{l}65 \\
\leq X<82\end{array}$ & 162 & $65,32 \%$ & Sedang \\
\hline & $X \geq 82$ & 46 & $18,54 \%$ & Tinggi \\
\hline
\end{tabular}

Berdasarkan tabel 4.10 di atas dapat diketahui pada variabel dukungan sosial diperoleh gambaran bahwa dukungan sosial pada siswa SMK Negri 4 Padang pada kategori tinggi yaitu berjumlah 49 orang $(19,75 \%)$, kategori sedang berjumlah 154 orang $(653,28 \%)$ dan 45 orang $(18,14 \%)$ untuk kategori rendah, sedangkan untuk variabel self regulated Learning pada kategori tinggi yaitu berjumlah 46 orang (18,54\%), kategori sedang berjumlah 162 orang $(65,32 \%)$ dan 40 orang $(16,12 \%)$ untuk kategori rendah. Hal ini dapat disimpulkan bahwa rata-rata subjek penelitian memiliki dukungan sosial dan self regulated learning dalam kategori sedang.

\section{Sumbangan Efektif}

Besar sumbangan efektif dari variabel empatiterhadap variabel perilaku altruisme dapat ditentukan dengan menggunakan rumus koefisien determinan. Koefisien determinan adalah kuadrat dari koefisien korelasi yang dikali dengan $100 \%$ (Priyatno, $2008)^{[13]}$. Derajat koefisien determinan dicari dengan menggunakan rumus sebagai berikut :

$$
K P=r^{2} \cdot 100 \%
$$

Keterangan:

$$
\begin{aligned}
& \mathrm{KP}=\text { Korelasi parsial } \\
& \mathrm{r}=\text { Nilai koefisien } \\
& \text { korelasi } \\
& \mathrm{KP}=\mathrm{r}^{2} \times 100 \% \\
& =(0,542)^{2} \times 100 \% \\
& =0,293 \times 100 \% \\
& =29.30 \% \\
& =29 \%
\end{aligned}
$$

Berdasarkan rumus tersebut maka dapat ditentukan bahwa besarnya sumbangan dukungan sosial terhadap self regulated learning adalah sebesar $29 \%$.

\section{Uji Validitas dan Reliabilitas}

Berdasarkan uji validitas dan reliabilitas pada penelitian ini menggunakan teknik product moment dan Alpha Cronbach. Diperoleh nilai indeks daya beda item skala dukungan sosial bergerak dari $r_{i x}=0,301$ sampai dengan $r_{i x}=0,762$ dengan koefisien reliabilitas $\alpha=0,925$. Berdasarkan hasil uji coba tersebut, maka dari 40 item diperoleh 28 item yang valid dan 12 item yang gugur dan untuk skala self regulated learning diperoleh nilai indeks daya beda item bergerak dari $r_{i x}=0,303$ sampai dengan $\mathrm{r}_{\mathrm{ix}}=0,843$ dengan koefisien reliabilitas $\alpha=$ 0,927 Berdasarkan hasil uji coba tersebut, maka dari 30 item diperoleh 25 item yang valid dan 5 item yang gugur. 


\section{DISKUSI}

Berdasarkan hasil uji korelasi product moment pearson yang dilakukan dengan bantuan IBM SPSS versi 20.0, diperoleh nilai koefisien korelasi $r=0,542$ dengan nilai $(p)$ sig $=0,000$, karena nilai (p) sig 0,000<0,01 maka hipotesis diterima. Hasil ini menunjukkan bahwa terdapat hubungan signifikan antara dukungan sosial dengan self regulated learning dengan arah positif, artinya semakin tinggi dukungan sosial, maka semakin tinggi self regulated learning, sebaliknya semakin rendah dukungan sosial, maka semakin rendah self regulated learning siswa SMK Negri 4 Padang.

Johnson dan Johnson (dalam Handono dan Bashori, 2013) menyatakan bahwa dukungan sosial merupakan makna dari hadirnya orang lain yang dapat diandalkan untuk dimintai bantuan, dorongan, dan penerimaan apabila individu yang bersangkutan mengalami kesulitan dalam berinteraksi dengan lingkungan. Jadi pada dasarnya dukungan sosial merupakan hubungan yang sifatnya menolong disaat individu sedang mengalami persoalan atau kesulitan, baik berupa informasi maupun bantuan nyata, sehingga membuat individu merasa diperhatikan, bernilai, dan dicintai.

Menurut Zimmerman (dalam Hartati,2016). individu yang memiliki kemampuan dalam mengatur dirinya menunjukkan kualitas kualitas dalam mencapai tujuannya yaitu mereka dengan sadar mengunakan strategi untuk berhasil, mereka merencanakan, mengendalikan, dan mengarahkan usaha mental mereka, mereka mengunakan kepercayaan dirinya dan emosi dalam meningkatkan prestasi mereka, mereka mengendalikan usaha dan waktu mereka, mereka memilih lingkungan pekerjaan yang baik dan cocok untuk dirinya, mereka mengambil inisiatif atau tindakan dalam tugas belajarnya dan perencanaan dalam akademiknya, mereka memiliki strategi dalam untuk memelihara usaha, konsentrasi.

Siswa yang merasa memperoleh dukungan sosial secara emosional merasa lega karena diperhatikan oleh orangtua, guru, dan teman mendapat saran atau kesan yang menyenangkan pada siswa, agar siswa dapat mencari jalan keluar untuk memecahkan masalahnya dalam belajar. Hasil penelitian ini selaras dengan penelitian yang dilakukan Adicondro dan Purnamasari (2011), faktor dukungan sosial merupakan salah satu yang hal dapat mempengaruhi self-regulated learning.

Berdasarkan hasil analisis determinasi, diperoleh nilai $\mathrm{R}$ Square sebesar 0,294. Berdasarkan hasil uraian dan pembahasan diatas, hasil penelitian ini telah mampu menjawab hipotesis mengenai hubungan antara dukungan dengan self-regulated learning. Sumbangan dukungan sosial terhadap self regulated learning adalah sebesar $29 \%$ dan $71 \%$ lagi faktor lain yang mempengaruhi self regulated learning adalah faktor pribadi seperti: Kecerdasan dan motivasi, serta faktor perilaku seperti: evaluasi diri terhadap hasil belajar zimmerman (dalam Aziz, 2017).

\section{KESIMPULAN}

Berdasarkan hasil analisis data kuantitatif yang diperoleh melalui penelitian ini maka dapat diperoleh kesimpulan bahwa Terdapat hubungan yang cukup kuat dengan arah positif dan signifikan antara dukungan sosial dengan selfregulated Learning pada siswa di SMK Negri 4 Padang. Terlihat dari hasil korelasi antara variabel dukungan sosial dengan self regulated learning pada siswa yang cukup kuat dengan arah positif, artinya hipotesis diterima jika dukungan sosial tinggi maka self regulated learning juga tinggi, sebaliknya jika dukungan sosial rendah maka self regulated learning akan rendah.

\section{Saran}

Berdasarkan hasil penelitian yang telah dilakukan, maka peneliti mencoba memberikan beberapa saran yang dapat dijadikan sebagai pertimbangan yang dapat bermanfaat, diantaranya:

1. Untuk Siswa

Secara umum memiliki tingkat self-regulated learning yang sedang, oleh karena itu disarankan untuk meningkatkan self-regulated learning dengan cara berkeinginan untuk menjadi lebih kompeten dengan memiliki daya saing mampu untuk meningkatkan prestasi, dan mengatur dan mengelola semua kemampuan yang dimiliki, 
memotivasi diri untuk lebih baik dan meningkatkan kesadaran untuk belajar.

\section{Untuk Sekolah}

Sekolah juga diharapkan dapat terus mempertahankan dan meningkatkan dukungan terhadap para siswa dalam kegiatan belajar, memberikan penghargaan bagi siswa yang berprestasi, meningkatkan kontrol pengawasan terhadap lingkungan pendidikan dan sosial di masyarakat.

3. Untuk Orangtua Siswa

Mempertahankan bagi yang sudah memberi dukungan sosial tinggi kepada siswa dan terus meningkatkan dukungan jika dukungan yang diberikan belum maksimal kepada siswa dalam proses kegiatan belajarnya. Dukungan terhadap siswa juga dapat diberikan dalam bentuk perhatian, memberi semangat, dan mendampingi dalam kegiatan belajar yang dilakukan. Hal ini dapat menghindarkan siswa memiliki self regulated learning yang rendah.

4. Untuk Peneliti Selanjutnya

Penelitian ini diharapkan dapat menjadi masukan bagi peneliti lain yang hendak melakukan penelitian pada bidang kajian yang sama. Penelitian ini diharapkan dapat menjadi referensi untuk membantu peneliti yang memiliki satu atau lebih variabel yang sama sehingga mampu melaksanakan penelitian dengan lebih baik dan melakukan penyempurnaan pada prosedur serta alat ukur yang digunakan. Besarnya sumbangan efektif dukungan sosial dengan self regulated learning adalah sebesar $29 \%$ sedangkan 71 $\%$ sisanya dipengaruhi oleh factor lain seperti motivasi, factor lingkungan sekolah dan kecerdasan.

\section{DAFTAR PUSTAKA}

Afriansyah, Donal. (2014). Hubungan Antara Dukungan Orang Tua Dengan Hasil Belajar Siswa Pada Pembelajaran IPS Di Kelas VI SD Negeri 68 Kota Bengkulu. Skripsi. Bengkulu : Universitas Bengkulu.

Ali, Mohammad. dan Mohammad Asrori. 2012. Psikologi Remaja Perkembangan Peserta Didik. Jakarta: PT. Bumi Aksara.

Apollo, Cahyadi. A. 2012. Konflik Peran Ganda Perempuan Menikah Yang Bekerja Ditinjau Dari Dukungan Sosial Keluarga Dan Penyesuaian Diri. Jurnal Psikologi No.02 Juli 2012 Fakultas Psikologi Universitas Katolik Widya Mandala Madiun.

Azwar, Saifuddin. 2014. Metode Penelitian. Yogyakarta: Pustaka Belajar.

Saifuddin. 2016. Penyususunan Skala Psikologi Edisi 2. Yogyakarta: Pustaka Pelajar

Fasikhah, Siti Suminarti \& Fatimah, Siti. (2013). Self Regulated Learing Dalam Meningkatkan Prestasi Akademik Mahasiswa. Jurnal Psikologi Vol. 01, No.01 Fakultas Psikologi, Universitas Muhammadiyah Malang

Hadiati, Rini Mukti. (2013). Pebedaan Minat

Belajar Dan Prestasi Belajar Siswa Terhadap Pemilihan Sekolah Lanjutan Atas di SMP Negri 1 Sambirejo. Skripsi. Universitas Sebelas Maret Surakarta

Herdiati. (2014). Pengaruh Self-Regulated Learning Dan Dukungan Sosial Terhadap Proktatinasi Akademik Mahasiswa Psikologi. Skripsi. Jakarta : Universitas Islam Negri Syarif Hidayatullah

Kadi, Ari prima Usman.(2016). Hubungan Kepercayaandiri Dan Self Regulated Learning Terhadap Proktatinasi Akademik Pada Mahasiwa Psikologi 2013. Jurnal 
140 Jurnal Al-Qalb, Jilid 10, Nomor 2, Oktober 2019, hlm. 133-140

Psikologi. Universitas Mulawarman.

Lubis, Rifi Hamdani dkk,(2016). Hubungan Antara Dukungan Sosial Dan Kecerdasan Emosional Dengan Self Regulated Learning Siswa. Jurnal Magister Psikologi UMA Vol 8 No . Medan: Universitas Islam Negeri Sumatera Utara.
Smet, Bart. 1994. Psikologi Kesehatan. Jakarta: PT. Gramedia Widiasarana Indonesia

Sugiyono. 2014. Metode Penelitian Kuantitatif Kualitatif dan $R \& D$. Bandung: Alfabeta.

Priyatno, D. 2008. Mandiri Belajar SPSS.Yogyakarta: Mediakom. 